\title{
A COMPARISON OF THE ACTIVATION ENERGY OF VISCOUS FLOW FOR HEN EGG-WHITE LYSOZYME OBTAINED ON THE BASIS OF DIFFERENT MODELS OF VISCOSITY FOR GLASS-FORMING LIQUIDS
}

\author{
KAROL MONKOS \\ Department of Biophysics, Medical University of Silesia, H. Jordana 19, 41-808 Zabrze 8, Poland
}

Received January 20, 2011; accepted March 22, 2011; published online March 27, 2011

\begin{abstract}
The paper presents the results of viscosity determinations on aqueous solutions of hen egg-white lysozyme at a wide range of concentrations and at temperatures ranging from $5^{\circ} \mathrm{C}$ to $55^{\circ} \mathrm{C}$. On the basis of these measurements and different models of viscosity for glass-forming liquids, the activation energy of viscous flow for solutions and the studied protein, at different temperatures, was calculated. The analysis of the results obtained shows that the activation energy monotonically decreases with increasing temperature both for solutions and the studied protein. The numerical values of the activation energy for lysozyme, calculated on the basis of discussed models, are very similar in the range of temperatures from $5^{\circ} \mathrm{C}$ to $35^{\circ} \mathrm{C}$.
\end{abstract}

\section{INTRODUCTION}

One of the most important quantity characterizing the viscous flow of proteins in solutions is an activation energy of viscous flow $\Delta \mathrm{E}$. It is usually defined as a minimum energy required for a molecule to escape the influence of its neighbouring molecules (Vinogradov \& Malkin, 1980). Experimentally, it can be obtained from the slope of the line that represents the dependence of viscosity $\eta$ (in logarithmic scale) of liquid on reciprocal of the absolute temperature $\left(\mathrm{T}^{-1}\right)$ in which the viscosity was measured. Thus obtained $\Delta \mathrm{E}$ is only an average value from the studied range of temperatures because, in general, the activation energy depends on temperature. The activation energy at a single-chosen temperature is equal to the slope of the tangent to the curve in a concrete point on the Arrhenius plot, i.e. the plot of $\ln \eta$ on $\mathrm{T}^{-1}$. It means that for solutions, in which $\Delta \mathrm{E}$ depends on both temperature and concentration, the activation energy can be defined in the following way:

$$
\Delta E(c, T)=R \frac{d \ln \eta(c, T)}{d T^{-1}}
$$

$\mathrm{R}$ is a gas constant. In practice, it is not possible to measure the viscosity of one solution for too many temperatures, when measurements are conducted at a wide range of temperatures. To establish the dependence of the activation energy of viscous flow on temperature it is rather reasonable to use a functional dependence of viscosity on temperature in the above definition. In the present paper such functional dependence is taken from the three models of viscous flow for glass-forming systems: from free-volume model, Avramov's model and power-law model. The obtained formulae for the dependence of $\Delta \mathrm{E}(\mathrm{c}, \mathrm{T})$ on temperature have been used to the calculation of the activation energy of viscous flow of hen egg-white lysozyme (HEWL) molecules at different temperatures.

HEWL is a well-known enzyme that acts as a glycoside hydrolase. It is a small globular protein of the molecular mass $\mathrm{M}_{\mathrm{p}}=14320$ Da (Squire \& Himmel, 1979) and well-recognized three dimensional structure (Smith et al., 1993). It serves as a model protein for different biophysical and biochemical studies. Structure, dynamics and hydration of HEWL have been studied by a wide range of experimental techniques such as NMR spectroscopy (Smith et al., 1993; Gregory et al., 1993; Diakova et al., 2007; Baranowska \& Olszewski, 1996), dielectric spectroscopy (Miura et al., 1994; Bonincontro et al., 2004; Knab et al., 2006; English et al., 2009; Woods, 2010), Fourier transform infrared spectroscopy (Hadden et al., 1995; Turula \& de Haseth, 1996), X-ray crystallography (Yagi et al., 2009), neutron scattering (Lushnikoy et al., 2009), circular dichroism (Maroufi et al., 2008) and viscometry (Monkos, 1997). Theoretical treatment of those problems one can also find in the literature (Zhou, 1995; Roth et al., 1996). 


\section{MATERIALS}

HEWL used in this study was purchased from Sigma Chemical and was used without further purification for all the measurements. Aqueous solutions were prepared by dissolving the crystallized HEWL in distilled water. In the next step, the solutions were treated with filter paper in order to remove possible undissolved dust particles. The samples were stored in a refrigerator until just prior to viscometry measurements, when they were warmed from $5^{\circ} \mathrm{C}$ to $55^{\circ} \mathrm{C}$. The $\mathrm{pH}$ values of such prepared samples were measured by using $\mathrm{pH}$ meter. Those values, in the whole range of concentrations, fluctuated slightly in the vicinity of neutral $\mathrm{pH}$ (7.0).

\section{VISCOMETRY}

Capillary viscosity measurements were made using an Ubbelohde microviscometer placed in a water bath controlled thermostatically with a precision of $\pm 0.1^{\circ} \mathrm{C}$. The same viscometer was used for all measurements. A solution passed once through the viscometer before any measurements were conducted. Measurements started after several minutes delay to ensure that the system reached equilibrium. The viscosity of HEWL solutions was measured for concentrations from $24.9 \mathrm{~kg} / \mathrm{m}^{3}$ up to $343 \mathrm{~kg} / \mathrm{m}^{3}$ at temperatures ranging from $5^{\circ} \mathrm{C}$ to $55^{\circ} \mathrm{C}$ and, for most concentrations, in $5^{\circ} \mathrm{C}$ intervals. At the temperatures higher than $55^{\circ} \mathrm{C}$ the thermal denaturation occurs and the lower protein concentration the higher denaturation temperature. The viscosity of HEWL solutions has been previously studied by Lefebvre (Lefebvre, 1982). The author has shown that the flow of the solutions of HEWL in the native state is Newtonian for shear rates from 0 to at least $128.5 \mathrm{~s}^{-1}$ and up to a concentration of at least $370 \mathrm{~kg} / \mathrm{m}^{3}$. It justifies the use of a capillary viscometer in our case.

Solutions densities were measured by weighing. For this purpose, $(0.3 \pm 0.001) \mathrm{ml}$ of a solution was weighed with the precision of $\pm 0.1 \mathrm{mg}$. HEWL concentrations were determined using a dry weight method in which samples were dried at high temperature for several hours. The details of the method are presented elsewhere (Monkos \& Turczynski, 1991).

\section{RESULTS AND DISCUSSION}

As mentioned above the activation energy of viscous flow can be obtained experimentally from measurements of the liquid viscosity at different temperatures and from the slope of the line on the Arrhenius plot. This method was successfully applied for many liquids in the case when the viscosity measurements were conducted in a relatively narrow range of temperatures (Hayakawa et al., 1991; Bourret et al., 1994; Lopez da Silva et al., 1994; Jauregui et al., 1995; de Paula \& Rodrigues, 1995; Kar \& Arslan, 1999; de Vasconcelos et al., 2000; Desbrieres, 2002; Durand, 2007; Knoben et al., 2007). In our case, viscosity measurements were made in a broad range of temperatures. It appears that the plot of $\ln \eta$ on $\mathrm{T}^{-1}$ for each concentration of HEWL is nonlinear. This means that the activation energy of those solutions depends on temperature.

In a streamline flow of a solution, molecules of both dissolved proteins and water take part. Therefore, one can assume that the activation energy of a solution at a given temperature $\Delta \mathrm{E}(\mathrm{c}, \mathrm{T})$ is a superposition of the activation energy of dissolved protein molecules $\Delta \mathrm{E}_{\mathrm{p}}(\mathrm{T})$ and water molecules $\Delta \mathrm{E}_{\mathrm{w}}(\mathrm{T})$ at the same temperature: $\Delta \mathrm{E}(\mathrm{c}, \mathrm{T})=\mathrm{X}_{\mathrm{p}} \Delta \mathrm{E}_{\mathrm{p}}(\mathrm{T})+\mathrm{X}_{\mathrm{w}} \Delta \mathrm{E}_{\mathrm{w}}(\mathrm{T})$. The symbols $\mathrm{X}_{\mathrm{p}}$ and $X_{w}$ denote molar fractions of the dissolved proteins and water, respectively. This assumption leads to the following dependence of the activation energy of a solution on concentration (Monkos, 1996):

$$
\begin{aligned}
& \Delta E(c, T)= \\
& \frac{c}{\alpha-\beta c}\left[\Delta E_{p}(T)-\Delta E_{w}(T)\right]+\Delta E_{w}(T)
\end{aligned}
$$

In this equation $\alpha=\rho_{\mathrm{w}} \mathrm{M}_{\mathrm{h}} / \mathrm{M}_{\mathrm{w}}$ and $\beta=\alpha \xi-1$. The quantities $\rho_{\mathrm{w}}, \xi, \mathrm{M}_{\mathrm{h}}$ and $\mathrm{M}_{\mathrm{w}}$ denote the water density in $\mathrm{kg} / \mathrm{m}^{3}$, the effective specific volume of a protein and the molecular masses of the dissolved protein and water, respectively. The effective specific volume is the constant of proportionality between the specific molar volume and the molar mass of a macrosolute (Zimmerman \& Minton, 1993).

Proteins in a solution are surrounded by a hydration shell of water molecules. Water molecules which fill cavities inside of a protein and ordered water molecules on the protein surface are an integral part of the protein and therefore contribute to its hydrodynamic mass. The molecular mass of hydrated protein can be considered as a sum of the molecular mass of unhydrated protein $M_{p}$ and the mass of water bounded with the protein: $\mathrm{M}_{\mathrm{h}}=$ $\mathrm{M}_{\mathrm{p}}(1+\delta)$. The quantity $\delta$ means the level of protein hydration and is equal to the amount of grams of water associated with the protein per gram of protein. HEWL does not reveal its enzymatic activity in the unhydrated state. The onset of activity is observed when at least 0.2 $\mathrm{g}$ of water is added per $1 \mathrm{~g}$ of protein (Pérez et al., 1999). Full hydration for HEWL is achieved at $\delta=0.38$ (Gregory et al., 1993; Pérez et al., 1999). It gives the hydrodynamic mass of HEWL $\mathrm{M}_{\mathrm{h}}=19762 \mathrm{Da}$. The effective specific volume of HEWL $\xi=2.6 \times 10^{-3} \mathrm{~m}^{3} / \mathrm{kg}$, was obtained previously (Monkos, 1997). To calculate 
the activation energy $\Delta \mathrm{E}_{\mathrm{p}}(\mathrm{T})$ for HEWL from equation (2) the activation energy of a solution $\Delta E(c, T)$ is needed. It can be established from the models of viscous flow for glass-forming systems.

\section{Free-volume model.}

According to this model a flow of liquid is possible thanks to movements of molecules into holes created by the surrounding molecules owing to density fluctuations (Vinogradov \& Malkin, 1980). The holes have to be large enough for the molecules to jump into. The free volume is defined as the space not occupied by the molecules, i.e. the difference between the specific volume of the liquid and the specific volume occupied by the molecules themselves. The application of the free-volume concept to glass-forming liquids by Williams, Landel and Ferry gave the viscositytemperature relationship which can be used from the glass transition temperature $\mathrm{T}_{\mathrm{g}}$ up to $\mathrm{T}_{\mathrm{g}}+100^{\circ} \mathrm{C}$. In the neighbourhood of glass transition temperature the viscosity of liquid reaches $10^{13}$ poise. The temperature at which liquid viscosity reaches infinite value is called the ideal glass transition temperature $T_{0}$. The free volume is equal to zero at $\mathrm{T}_{\mathrm{o}}$. The assumption that for temperatures higher than $T_{o}$ the free volume increases linearly with temperature, leads to the Vogel-Tammann-Fulcher's (VTF) equation (Vinogradov \& Malkin, 1980). For solutions, for which viscosity depends on both temperature and concentration, and with modification proposed by Angell (Angell, 1988), it has the following form:

$$
\eta(c, T)=W_{s}(c) \exp \left[\frac{F_{s}(c) T_{o, s}(c)}{T-T_{o, s}(c)}\right]
$$

The parameters $\mathrm{W}_{\mathrm{s}}(\mathrm{c}), \mathrm{F}_{\mathrm{s}}(\mathrm{c})$ and $\mathrm{T}_{\mathrm{o}, \mathrm{s}}(\mathrm{c})$ depend only on concentration. To fit the function from the above

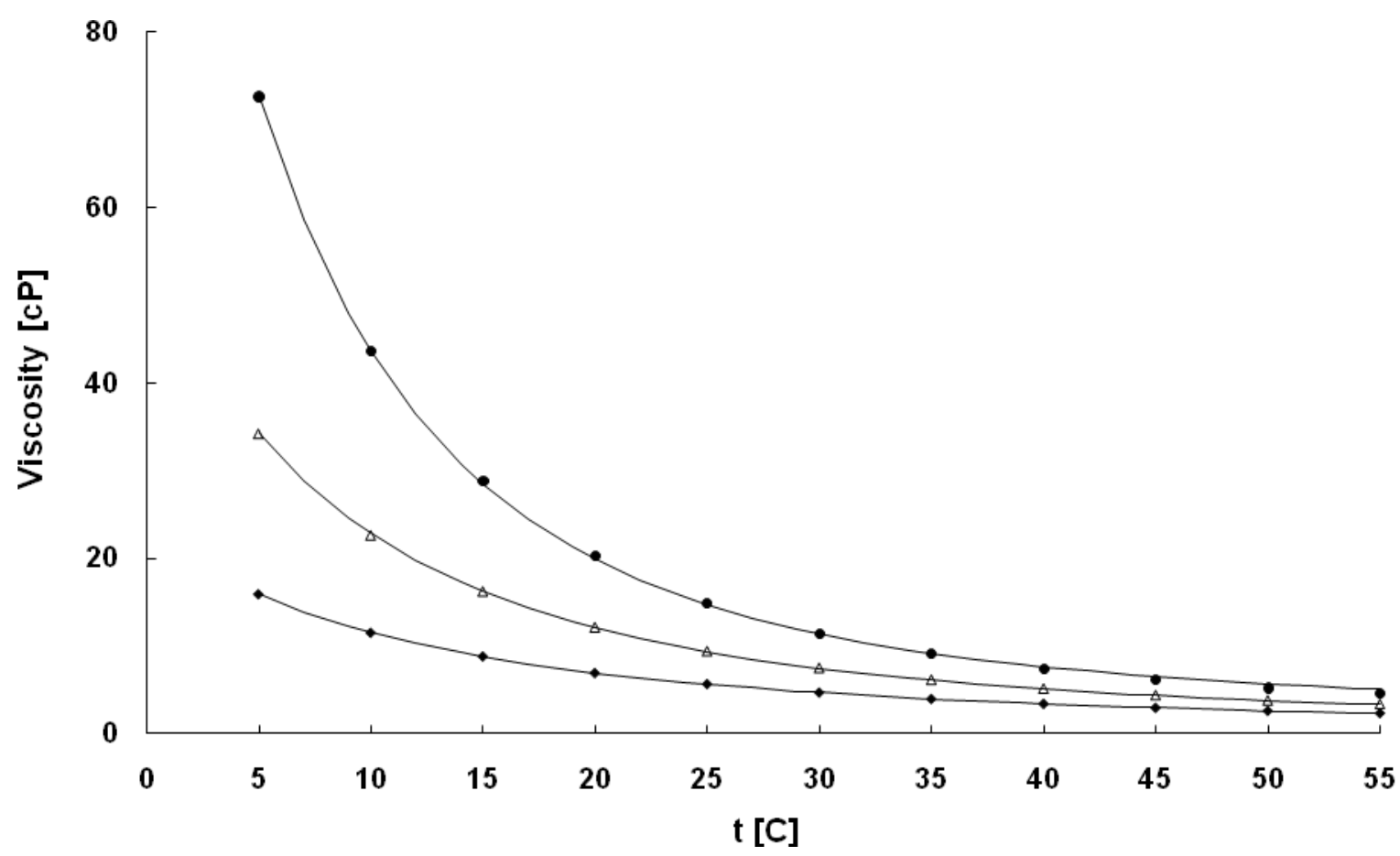

Fig. 1. Temperature dependence of the viscosity of HEWL aqueous solutions. The curves show the fit obtained by using Avramov's model with the parameters: $\eta_{\infty}=2.329 \mathrm{cP}, \Theta=319 \mathrm{~K}$ and $\alpha(\mathrm{c})=8.987$ for $\mathrm{c}=343 \mathrm{~kg} / \mathrm{m}^{3}(\bullet)$; free-volume model with the parameters: $\mathrm{W}_{\mathrm{s}}(\mathrm{c})=$ $0.235 \mathrm{cP}, \mathrm{T}_{\mathrm{o}, \mathrm{s}}(\mathrm{c})=221 \mathrm{~K}$ and $\mathrm{F}_{\mathrm{s}}(\mathrm{c})=1.275$ for $\mathrm{c}=322 \mathrm{~kg} / \mathrm{m}^{3}(\Delta)$; power-low model with the parameters: $\mathrm{A}(\mathrm{c})=5101 \mathrm{cP}, \mathrm{T}_{\mathrm{p}}(\mathrm{c})=253 \mathrm{~K}$ and $\mu(\mathrm{c})=1.785$ for $\mathrm{c}=296 \mathrm{~kg} / \mathrm{m}^{3}(\bullet)$.

equation to the experimental values of viscosity measured at different temperatures the numerical values of these parameters are necessary. They have been calculated, for all concentrations of HEWL, by applying the non-linear least squares method described in earlier paper (Monkos, 2008). Figure 1 shows the results of viscosity measurements for $\mathrm{c}=322 \mathrm{~kg} / \mathrm{m}^{3}$ and in the whole range of measured temperatures. The curve 
presents the fit to the experimental points according to the above relation. It can be seen that a very good fit over the whole range of temperatures has been obtained.

The VTF relation gives the functional dependence of the viscosity on temperature and can be used for obtaining the functional dependence of the activation energy of viscous flow. After insertion it into the definition (1), differentiation and simple transformations it is possible to obtain the following relation for the activation energy of a solution:

$$
\Delta E(c, T)=\frac{R F_{s}(c) T_{o, s}(c) T^{2}}{\left[T-T_{o, s}(c)\right]^{2}}
$$

Table 1. Numerical values of the parameters $T_{o, s}(c)$ and $F_{s}(c)$ from the free-volume model; $\Theta(c)$ and $\alpha(c)$ from Avramov's model and $\mathrm{T}_{\mathrm{p}}(\mathrm{c})$ and $\mu(\mathrm{c})$ from power-law model for all measured concentrations. They allow calculation of the activation energy of HEWL solutions from relations (4), (6) and (8), respectively.

\begin{tabular}{ccccccc}
\hline $\mathrm{c}\left[\mathrm{kg} / \mathrm{m}^{3}\right]$ & $\mathrm{T}_{\mathrm{o}, \mathrm{s}}(\mathrm{c})[\mathrm{K}]$ & $\mathrm{F}_{\mathrm{s}}(\mathrm{c})$ & $\Theta(\mathrm{c})[\mathrm{K}]$ & $\alpha(\mathrm{c})$ & $\mathrm{T}_{\mathrm{p}}(\mathrm{c})[\mathrm{K}]$ & $\mu(\mathrm{c})$ \\
\hline 24.9 & 165 & 2.52 & 363 & 3.48 & 230 & 1.56 \\
35.3 & 164 & 2.53 & 365 & 3.46 & 228 & 1.63 \\
42.6 & 162 & 2.64 & 375 & 3.28 & 225 & 1.70 \\
50.9 & 162 & 2.68 & 372 & 3.35 & 227 & 1.67 \\
63.3 & 156 & 3.13 & 399 & 3.00 & 225 & 1.75 \\
70.6 & 151 & 3.41 & 399 & 2.99 & 224 & 1.75 \\
76.8 & 155 & 3.19 & 383 & 3.21 & 227 & 1.71 \\
83.1 & 159 & 2.92 & 389 & 3.13 & 226 & 1.72 \\
92.4 & 153 & 3.32 & 393 & 3.09 & 228 & 1.69 \\
106 & 158 & 3.05 & 399 & 3.03 & 229 & 1.69 \\
109 & 158 & 3.03 & 392 & 3.12 & 227 & 1.74 \\
149 & 163 & 2.90 & 376 & 3.47 & 231 & 1.73 \\
202 & 182 & 2.15 & 355 & 4.17 & 239 & 1.69 \\
209 & 182 & 2.20 & 351 & 4.37 & 240 & 1.71 \\
239 & 193 & 1.84 & 345 & 4.78 & 244 & 1.71 \\
257 & 201 & 1.63 & 338 & 5.31 & 247 & 1.73 \\
296 & 211 & 1.43 & 331 & 6.25 & 253 & 1.78 \\
322 & 221 & 1.27 & 328 & 7.28 & 257 & 1.95 \\
343 & 227 & 1.25 & 319 & 8.99 & 259 & 2.18 \\
\hline
\end{tabular}

It appears that $\Delta \mathrm{E}(\mathrm{c}, \mathrm{T})$ depends only on two parameters from VTF equation: $F_{s}(c)$ and $T_{o, s}(c)$. Their numerical values for HEWL solutions, for all measured concentrations, are gathered in Table 1. Experimental values of the activation energy for HEWL solutions at temperature $5^{\circ} \mathrm{C}$, indirectly established from equation (4) are presented, in turn, in Figure 2. The function from equation (2) can now be fitted to these experimental values. At $\mathrm{c}=0$, the above equation gives the activation energy of water. Taking for water $\mathrm{F}_{\mathrm{s}}(0)=\mathrm{F}_{\mathrm{w}}=3.57$ and $\mathrm{T}_{\mathrm{o}, \mathrm{s}}(0)=\mathrm{T}_{\mathrm{o}, \mathrm{w}}=147 \mathrm{~K}$ one can calculate $\Delta \mathrm{E}_{\mathrm{w}}(\mathrm{T})$. This quantity decreases from $19.52 \mathrm{~kJ} / \mathrm{mol}$ (at $5^{\circ} \mathrm{C}$ ) to 14.25 $\mathrm{kJ} / \mathrm{mol}$ (at $55^{\circ} \mathrm{C}$ ). The activation energy of a protein $\Delta \mathrm{E}_{\mathrm{p}}(\mathrm{T})$ is the only unknown parameter in equation (2) if the activation energy of water is known. To calculate it, it is convenient to apply once more the least squares method. Thus calculated values of $\Delta \mathrm{E}_{\mathrm{p}}(\mathrm{T})$ for HEWL are shown in Table 2 . It can be seen that $\Delta \mathrm{E}_{\mathrm{p}}(\mathrm{T})$ decreases with increasing temperature.

\section{Avramov's model}

In Avramov's model (Avramov, 1998) it is assumed that molecules in a flowing liquid jump from the holes formed by the nearest neighbours to one of the adjoining holes. Moreover, it is assumed that viscosity of the liquid is inversely proportional to the average frequency of these jumps. During the jumps the molecule has to overcome some energy barrier. In the model it is assumed that the frequency of jumps is different for different molecules and for a given temperature, it decreases exponentially with increasing the energy barrier. The assumption that the jumps frequency follows a Poisson distribution allows calculation of the average jump frequency. As a final result the dependence of liquid viscosity on temperature can be obtained. For solutions this dependence can be written in the following way:

$$
\eta(c, T)=\eta_{\infty}(c) \exp \left[\frac{\Theta(c)}{T}\right]^{\alpha(c)}
$$

in which $\eta_{\infty}(\mathrm{c}), \Theta(\mathrm{c})$ and $\alpha(\mathrm{c})$ are parameters which depend on concentration. The calculations of these parameters were conducted by applying a non-linear regression procedure in the computational statistical program. Figure 1 shows the results of viscosity measurements for HEWL at $\mathrm{c}=343 \mathrm{~kg} / \mathrm{m}^{3}$. The curve shows the fit to the experimental points according to relation (5), with the parameters obtained by the 
mentioned above method. It can be seen that this function gives also very good fit over the whole range of measured temperatures.
As in the previous model, the function from relation (5) can be inserted into the definition (1). It gives the functional dependence of the activation energy of a solution on temperature in the following form:

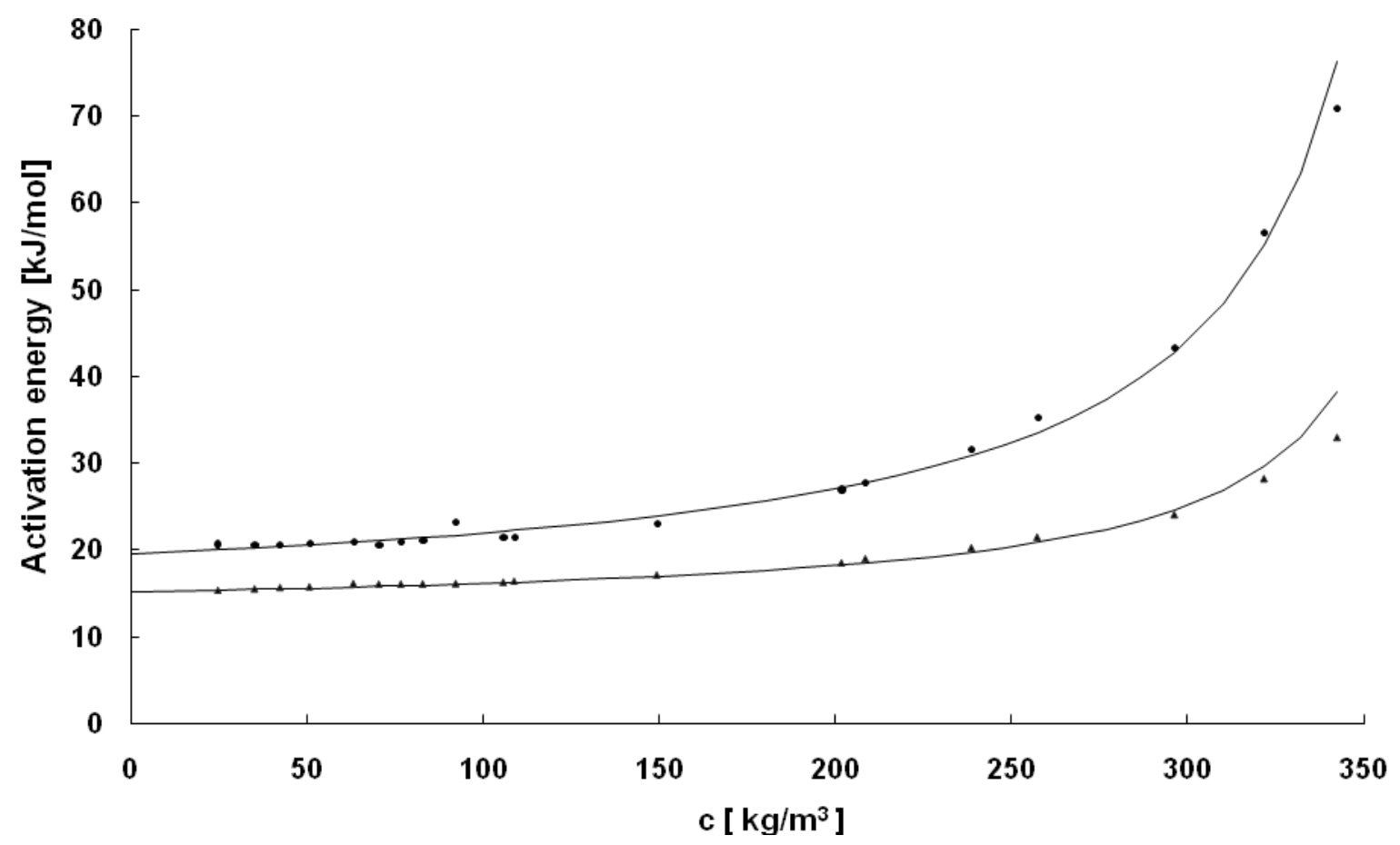

Fig. 2. Plot of the solution activation energy $\Delta \mathrm{E}(\mathrm{c}, \mathrm{T})$ versus concentration $\mathrm{c}$ for HEWL. Experimental points were obtained on the basis of Eqs. (4) and (8), respectively; the curves show the fit according to Eq. (2) with the parameters: $\alpha=1.098 \times 10^{6} \mathrm{~kg} / \mathrm{m}^{3}, \xi=2.6 \times 10^{-3} \mathrm{~m}^{3} / \mathrm{kg}$ and $\Delta \mathrm{E}_{\mathrm{p}}(\mathrm{T})=1.975 \times 10^{4} \mathrm{~kJ} / \mathrm{mol}, \Delta \mathrm{E}_{\mathrm{w}}(\mathrm{T})=19.52 \mathrm{~kJ} / \mathrm{mol}$ at $\mathrm{t}=5^{\circ} \mathrm{C}(\bullet) ; \Delta \mathrm{E}_{\mathrm{p}}(\mathrm{T})=8.027 \times 10^{3} \mathrm{~kJ} / \mathrm{mol}, \Delta \mathrm{E}_{\mathrm{w}}(\mathrm{T})=15.17 \mathrm{~kJ} / \mathrm{mol}$ at $\mathrm{t}=40^{\circ} \mathrm{C}$ ( $\mathbf{\Delta}$ ).

$$
\Delta E(c, T)=R T \alpha(c)\left[\frac{\Theta(c)}{T}\right]^{\alpha(c)}
$$

It can be seen that, as in the previous model, the dependence of the activation energy of a solution on temperature is characterized only by the two parameters: $\alpha(c)$ and $\Theta(c)$. Their numerical values for HEWL solutions, for all measured concentrations, are also gathered in Table 1. In Figure 3 the values of $\Delta \mathrm{E}(\mathrm{c}, \mathrm{T})$ for HEWL solutions at three temperatures, calculated on the basis of relation (6), are shown. At $\mathrm{c}=0$, the relation (5) describes very well the temperature dependence of viscosity of water. Taking the values of viscosity for water from the standard physicochemical tables the following numerical values of the parameters for water can be obtained: $\alpha(\mathrm{c})=\alpha_{\mathrm{w}}=2.958$ and $\Theta(\mathrm{c})=\Theta_{\mathrm{w}}=$ $395.7 \mathrm{~K}$. The values of the activation energy of water, calculated then from the equation (6) decrease from
$\Delta \mathrm{E}_{\mathrm{w}}(\mathrm{T})=19.41 \mathrm{~kJ} / \mathrm{mol}\left(\right.$ at $5^{\circ} \mathrm{C}$ ) up to $\Delta \mathrm{E}_{\mathrm{w}}(\mathrm{T})=14.04$ $\mathrm{kJ} / \mathrm{mol}\left(\right.$ at $55^{\circ} \mathrm{C}$ ). The curves in Figure 3 show the fit of the $\Delta \mathrm{E}(\mathrm{c}, \mathrm{T})$, obtained from the relation (2) with such calculated values of $\Delta \mathrm{E}_{\mathrm{w}}(\mathrm{T})$, to the experimental points. The activation energy of viscous flow for HEWL molecules $\Delta \mathrm{E}_{\mathrm{p}}(\mathrm{T})$ is then treated as adjustable parameter in equation (2). Its numerical values are presented in Table 2. As in previous model, $\Delta \mathrm{E}_{\mathrm{p}}(\mathrm{T})$ decreases with increasing temperature.

\section{Power-law model}

This is a phenomenological description of the dependence of viscosity on temperature (Taborek et al., 1986). The authors have remarked that for a quite different non-organic fluid systems the temperature variations of viscosity, over a broad temperature range, can be described by a power-type equation. This is the case for both pure liquids like water, methanol, benzene and so on, and solutions like aqueous solutions of lithium chloride. In the case of solutions the proposed formula has the following form: 


$$
\eta(c, T)=A(c)\left[T-T_{p}(c)\right]^{-\mu(c)}
$$

The parameters $A(c), T_{p}(c)$ and $\mu(c)$ depend only on concentration. These parameters were calculated for each concentration by applying a non-linear regression procedure in the computational statistical program. In Figure 1 the results of viscosity measurements for
HEWL solutions at $\mathrm{c}=296 \mathrm{~kg} / \mathrm{m}^{3}$, and the curve showing the fit to the experimental points according to relation (7) with the parameters obtained by the mentioned above method, are presented. It can be seen that formula (7) describes also very well the dependence of viscosity on temperature for aqueous solutions of HEWL, over the whole range of measured temperatures.

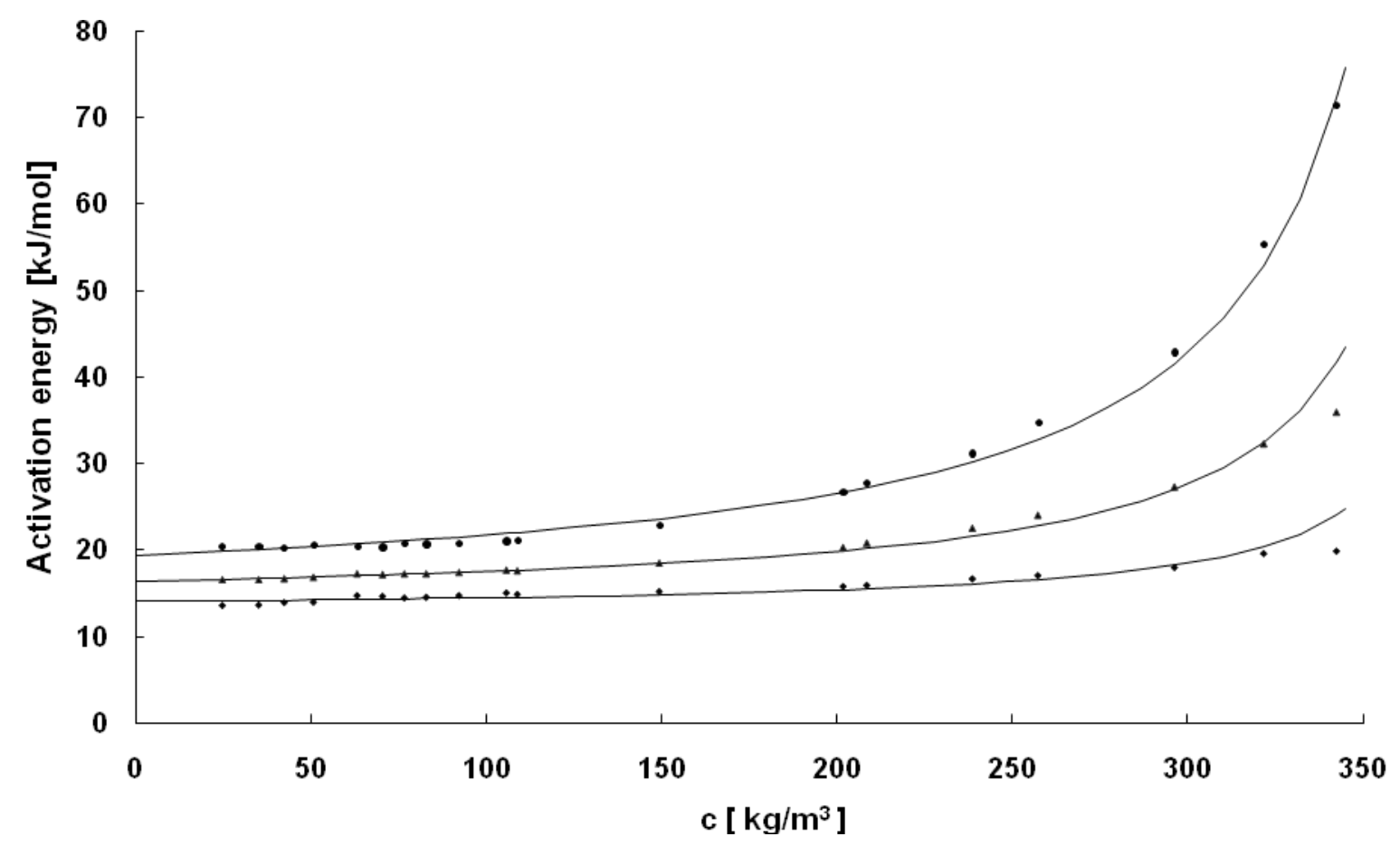

Fig. 3. Plot of the solution activation energy $\Delta \mathrm{E}(\mathrm{c}, \mathrm{T})$ versus concentration $\mathrm{c}$ for HEWL. Experimental points were obtained on the basis of Eq. (6); the curves show the fit according to Eq. (2) with the parameters: $\alpha=1.098 \times 10^{6} \mathrm{~kg} / \mathrm{m}^{3}, \xi=2.6 \times 10^{-3} \mathrm{~m}^{3} / \mathrm{kg}$ and $\Delta \mathrm{E}_{\mathrm{p}}(\mathrm{T})=1.9 \times 10^{4}$ $\mathrm{kJ} / \mathrm{mol}, \Delta \mathrm{E}_{\mathrm{w}}(\mathrm{T})=19,41 \mathrm{~kJ} / \mathrm{mol}$ at $\mathrm{t}=5^{\circ} \mathrm{C}(\bullet) ; \Delta \mathrm{E}_{\mathrm{p}}(\mathrm{T})=9.089 \times 10^{3} \mathrm{~kJ} / \mathrm{mol}, \Delta \mathrm{E}_{\mathrm{w}}(\mathrm{T})=16.4 \mathrm{~kJ} / \mathrm{mol}$ at $\mathrm{t}=30^{\circ} \mathrm{C}(\boldsymbol{\Delta}) ; \Delta \mathrm{E}_{\mathrm{p}}(\mathrm{T})=3.615 \times 10^{3}$ $\mathrm{kJ} / \mathrm{mol}, \Delta \mathrm{E}_{\mathrm{w}}(\mathrm{T})=14.04 \mathrm{~kJ} / \mathrm{mol}$ at $\mathrm{t}=55^{\circ} \mathrm{C}(\bullet)$.

The insertion of the function from equation (7) into the definition (1), leads to the following relation for the activation energy of a solution:

$$
\Delta E(c, T)=R \mu(c) \frac{T^{2}}{T-T_{p}(c)}
$$

According to this equation, as in two previous models, the activation energy of a solution depends only on the two parameters: $\mu(\mathrm{c})$ and $\mathrm{T}_{\mathrm{p}}(\mathrm{c})$. Their numerical values for HEWL solutions, for all measured concentrations, are also gathered in Table 1. It is worth to note, that the numerical values of the exponent " $\mu$ ", presented in the original paper (Taborek et al., 1986) for a different liquids, lie within a narrow range between 1.5 and 2.3. It can be seen in Table 1, that all values of the exponent " $\mu$ " obtained for aqueous solutions of HEWL lie also within this range. In Figure 2 the experimental values of the activation energy for HEWL solutions at temperature $40^{\circ} \mathrm{C}$, obtained from equation (8), are presented. Equation (7) describes the dependence of viscosity on temperature for water with the parameters: $\mathrm{A}(\mathrm{c})=\mathrm{A}_{\mathrm{w}}=$ $711 \mathrm{cP}, \mathrm{T}_{\mathrm{p}}(\mathrm{c})=\mathrm{T}_{\mathrm{p}, \mathrm{w}}=228.5 \mathrm{~K}$ and $\mu(\mathrm{c})=\mu_{\mathrm{w}}=1.574$. The activation energy of water, calculated from the equation (8), decreases then from $\Delta \mathrm{E}_{\mathrm{w}}(\mathrm{T})=20.4 \mathrm{~kJ} / \mathrm{mol}$ (at $5^{\circ} \mathrm{C}$ ) up to $\Delta \mathrm{E}_{\mathrm{w}}(\mathrm{T})=14.15 \mathrm{~kJ} / \mathrm{mol}$ (at $55^{\circ} \mathrm{C}$ ). The activation energy of viscous flow for HEWL molecules $\Delta E_{p}(T)$ calculated on the basis of the equation (2) is also shown in Table 2. 
Table 2. The mean values and standard errors of the activation energy of viscous flow $\Delta \mathrm{E}_{\mathrm{p}}(\mathrm{T})$ for HEWL molecules obtained from the studied models.

\begin{tabular}{cccc}
\hline $\mathrm{t}\left[{ }^{\circ} \mathrm{C}\right]$ & Free-volume model & Avramov's model & Power-law model \\
\hline 5 & $19.00 \pm 0.347$ & $18.90 \pm 0.273$ & $19.74 \pm 0.369$ \\
10 & $15.75 \pm 0.334$ & $15.98 \pm 0.290$ & $15.51 \pm 0.325$ \\
15 & $13.22 \pm 0.316$ & $13.23 \pm 0.271$ & $12.76 \pm 0.294$ \\
20 & $11.20 \pm 0.295$ & $11.31 \pm 0.310$ & $10.83 \pm 0.269$ \\
25 & $9.576 \pm 0.273$ & $9.450 \pm 0.310$ & $9.424 \pm 0.249$ \\
30 & $8.241 \pm 0.251$ & $7.839 \pm 0.304$ & $8.352 \pm 0.233$ \\
35 & $7.133 \pm 0.230$ & $6.445 \pm 0.293$ & $7.514 \pm 0.219$ \\
40 & $6.203 \pm 0.210$ & $5.237 \pm 0.279$ & $6.842 \pm 0.208$ \\
45 & $5.416 \pm 0.192$ & $4.188 \pm 0.263$ & $6.294 \pm 0.199$ \\
50 & $4.745 \pm 0.176$ & $3.276 \pm 0.246$ & $5.844 \pm 0.191$ \\
55 & $4.166 \pm 0.162$ & $2.482 \pm 0.228$ & $5.459 \pm 0.185$ \\
\hline
\end{tabular}

Comparison of the results of $\Delta E_{p}(T)$ for $H E W L$ molecules

It can be seen in Table 2, that each studied here model predicts that the activation energy of viscous flow of HEWL molecules monotonically decreases with increasing temperature. Moreover, the values of $\Delta \mathrm{E}_{\mathrm{p}}(\mathrm{T})$ for HEWL in the range of temperatures from $5^{\circ} \mathrm{C}$ to about $35^{\circ} \mathrm{C}$ are very similar. Substantial differences occur only for higher temperatures. It would be interesting to establish the factors which cause such changes of the activation energy with temperature.

The mean energy of translational heat motion of molecules $\langle\mathrm{E}\rangle$ is independent of molecular mass and increases with increasing temperature according to the well-known relation $\langle\mathrm{E}\rangle=1.5 \mathrm{kT}(\mathrm{k}-$ Boltzmann constant). At the studied here range of temperatures $<\mathrm{E}>$ increases from $5.76 \times 10^{-21} \mathrm{~J}$ (at $5^{\circ} \mathrm{C}$ ) up to $6.796 \times 10^{-21} \mathrm{~J}$ (at $55^{\circ} \mathrm{C}$ ). So, at $55^{\circ} \mathrm{C}<\mathrm{E}>$ is only 1.18 times greater than at $5^{\circ} \mathrm{C}$. It means that changes of the translational heat motion energy of HEWL molecules with temperature can not be responsible for such great changes of their activation energy with temperature.

As mentioned above the $\mathrm{pH}$ values of the studied here solutions were in the vicinity of neutral $\mathrm{pH}(7.0)$, i.e. were outside of isoelectric point (pI) for HEWL, which lies in the range of $(11-11.2)$ (Young, 1963). Proteins have the unusually large dipole moment in comparison with the dipole moment of water molecules. For HEWL molecules it is equal to $121 \mathrm{D}$ (Takashima, 2001). When the $\mathrm{pH}$ of the proteins solutions is outside of their isoelectric point the attractive dipole-dipole interactions between proteins are partially balanced by the repulsive interactions between their net charges. In consequence the total electrostatic interactions between proteins molecules are week. This suggests that electrostatic protein-protein interactions are not responsible for such great changes of the activation energy of HEWL molecules with temperature. The additional argument supporting this conclusion appears from an analysis of changes of the Huggins coefficient $\mathrm{k}_{1}$ with temperature. As is well-known, $\mathrm{k}_{1}$ is the quantitative measure of the intermolecular interactions (Dreval et al., 1973). In the case of strongly interacted molecules in solution the Huggins coefficient sharply increases with increasing temperature (Desbrieres et al., 1996). The Huggins coefficient for HEWL in aqueous solutions has been obtained previously (Monkos, 1997). It appears that $\mathrm{k}_{1}$ increases in this case from 1.35 (at $5^{\circ} \mathrm{C}$ ) up to 1.58 (at $55^{\circ} \mathrm{C}$ ). So, at $55^{\circ} \mathrm{C}$ it is only 1.17 times greater than at $5^{\circ} \mathrm{C}$. This confirms the statements that the interactions between HEWL molecules in the studied conditions are week.

Protein-solvent interactions, in turn, influence on the intrinsic viscosity $[\eta]$ (Pamies et al., 2008). This quantity is a measure of the contribution of a protein to the viscosity of the solution in which it is dissolved. For HEWL aqueous solutions it has been also obtained previously (Monkos, 1997). It decreases monotonically with increasing temperature from $3.05 \times 10^{-3} \mathrm{~m}^{3} / \mathrm{kg}$ (at $5^{\circ} \mathrm{C}$ ) up to $2.41 \times 10^{-3} \mathrm{~m}^{3} / \mathrm{kg}$ (at $55^{\circ} \mathrm{C}$ ). It means that at $5^{\circ} \mathrm{C}[\eta]$ is 1.27 times greater than at $55^{\circ} \mathrm{C}$. It appears that changes of $\langle\mathrm{E}\rangle, \mathrm{k}_{1}$ and $[\eta]$ with temperature are very small in comparison with changes of $\Delta \mathrm{E}_{\mathrm{p}}(\mathrm{T})$ with temperature. This strongly suggests that changes of the translational heat motion energy with temperature, protein-protein and protein-solvent interactions are not responsible for changes of the activation energy of HEWL molecules in solutions with temperature outside of isoelectric point. To explain these changes probably some hydrodynamic quantities, characterizing proteins in solutions, should be taken into account. This will be the subject of further investigations.

\section{CONCLUSIONS}

Functional dependences of the viscosity on temperature taken from the three models of viscosity for 
glass-forming systems: from free-volume model, Avramov's model and power-law model give very good fit to the experimental values of viscosity for HEWL aqueous solutions at temperatures from $5^{\circ} \mathrm{C}$ to $55^{\circ} \mathrm{C}$ and in a wide range of concentrations. For each model, the functional dependence of the viscosity on temperature and the strict definition of the activation energy of viscous flow allow obtaining the functional dependence of the activation energy of a solution on temperature. Taking into account that the activation energy of a solution is a superposition of the activation energy of dissolved protein molecules $\Delta \mathrm{E}_{\mathrm{p}}(\mathrm{T})$ and water molecules $\Delta \mathrm{E}_{\mathrm{w}}(\mathrm{T})$, the numerical values of $\Delta \mathrm{E}_{\mathrm{p}}(\mathrm{T})$ for HEWL molecules are possible to obtain. Each model predicts that $\Delta \mathrm{E}_{\mathrm{p}}(\mathrm{T})$ for HEWL monotonically decreases with increasing temperature. Moreover, the numerical values of $\Delta \mathrm{E}_{\mathrm{p}}(\mathrm{T})$ for HEWL, obtained from each model, are very similar in the range of temperatures from $5^{\circ} \mathrm{C}$ to about $35^{\circ} \mathrm{C}$. For higher temperatures substantial differences in the obtained values of $\Delta \mathrm{E}_{\mathrm{p}}(\mathrm{T})$ exist. Each model predicts great changes of the activation energy of HEWL with temperature. However, the molecular mechanism of such changes is not clear. One can only state that changes of the translational heat motion energy with temperature, protein-protein and protein-solvent interactions can not be responsible for it.

\section{REFERENCES}

Angell C.A. (1988). Perspective on the glass transition. J. Phys. Chem. Solids 8, 863-871.

Avramov I. (1998). Viscosity of glassforming melts. J. NonCryst. Solids 238, 6-10.

Baranowska H.M., Olszewski K.J. (1996). The hydration of proteins in solutions by self-diffusion coefficients NMR study. Biochim. Biophys. Acta 1289, 312-314.

Bonincontro A., Cinelli S., Onori G., Stravato A. (2004). Dielectric behavior of lysozyme and ferricytochrome-c in water/ethylene-glycol solutions. Biophys. J. 86, 1118-1123.

Bourret E, Ratsimbazafy V, Maury L, Brossard C. (1994). Rheological behavior of saturated polyglycolysed glycerides. J. Pharm. Pharmacol. 46, 538-541.

Desbrieres J. (2002). Viscosity of semiflexible chitosan solutions: Influence of concentration, temperature, and role of intermolecular interactions. Biomacromolecules 3, 342-349.

Desbrieres J., Martinez C., Rinaudo M. (1996). Hydrophobic derivatives of chitosan: Characterization and rheological behavior. Int. J. Biol. Macromol. 19, 21-28.

de Paula RCM, Rodrigues JF. (1995). Composition and rheological properties of cashew tree gum, the exudates polysaccharide from Anacardium occidentale L. Carbohydr. Polym. 26, 177-181.

de Vasconcelos CL, de Azevedo FG, Pereira MR, Fonseca JLC. (2000). Viscosity-temperature-concentration relationship for starch-DMSO-water solutions. Carbohydr. Polym. 41, 181-184.

Diakova G., Goddard Y.A., Korb J.P., Bryant R.G. (2007). Changes in protein structure and dynamics as a function of hydration from H-1 second moments. J. Mag. Res. 189, 166172.

Dreval V.E., Botvinnik G.O., Malkin A.Ya. (1973). Approach to generalization of concentration dependence of zero-shear viscosity in polymer solutions. J. Polym. Sci. 11, 1055-1076.

Durand A. (2007). Aqueous solutions of amphiphilic polysaccharides: Concentration and temperature effect on viscosity. Eur. Polym. J. 43, 1744-1753.

English N.J., Solomentsey G.Y., O’Brien P. (2009). Nonequilibrium molecular dynamics study of electric and lowfrequency microwave fields on hen egg white lysozyme. $J$. Chem. Phys. 131, 035106.

Gregory R.B., Gangoda M., Gilpin R.K., Su W. (1993). The influence of hydration on the conformation of lysozyme studied by solid-state ${ }^{13} \mathrm{C}-\mathrm{NMR}$ spectroscopy. Biopolymers 33, 513-519.

Hadden J.M., Chapman D., Lee D.C. (1995). A comparison of infrared spectra of proteins in solution and crystalline forms. Biochim. Biophys. Acta 1248, 115-122.

Hayakawa E, Furuya K, Kuroda T, Moriyama M, Kondo A. (1991). Viscosity study on the self-association of doxorubicin in aqueous solution. Chem. Pharm. Bull. 39, 12821286.

Jauregui B, Muñoz ME, Santamaria A. (1995). Rheology of hydroxyethylated starch aqueous systems. Analysis of gel formation. Int. J. Biol. Macromol. 17, 49-54.

Kar F, Arslan N. (1999). Effect of temperature and concentration on viscosity of orange peel pectin solutions and intrinsic viscosity-molecular weight relationship. Carbohydr. Polym. 40, 277-284.

Knab J., Chen J.Y., Markelz A. (2006). Hydration dependence of conformational dielectric relaxation of lysozyme. Biophys. J. 90, 2576-2581.

Knoben W, Besseling NAM, Cohen Stuart MA. (2007). Rheology of a reversible suprmolecular polymer studied by comparison of the effects of temperature and chain stoppers. $J$. Chem. Phys. 126, 024907.

Lefebvre J. (1982). Viscosity of concentrated protein solutions. Rheol. Acta 21, 620-625.

Lopez da Silva JA, Gonçalves MP, Rao MA. (1994). Influence of temperature on the dynamics and steady-shear rheology of pectin dispersions. Carbohydr. Polym. 23, 77-87.

Lushnikoy S.G., Svanidze A.V., Gvasaliya S.N., Torok G., Rosta L., Sashin I.L. (2009). Fractal properties of lysozyme: A neutron scattering study. Phys. Rev. E 79, 031913.

Maroufi B., Ranibar B., Khajeh K., Naderi-Manesh H., Yaghoubi H. (2008). Structural studies of hen egg-white lysozyme dimer. Comparison with monomer. Biochim. Biophys. Acta 1784, 1043-1049.

Miura N., Asaka N., Shinyashiki N., Mashimo S. (1994). Microwave dielectric study on bound water of globule proteins in aqueous solution. Biopolymers 34, 357-364.

Monkos K. (1996). Viscosity of bovine serum albumin aqueous solutions as a function of temperature and concentration. Int J Biol Macromol. 18, 61-68.

Monkos K. (1997). Concentration and temperature dependence of viscosity in lysozyme aqueous solutions. Biochim. Biophys. Acta 1339, 304-310.

Monkos K. (2008). Analysis of the viscosity-temperatureconcentration dependence for dimeric bovine $\beta$-lactoglobulin aqueous solutions on the basis of the Vogel-TammannFulcher's equation. Curr. Top. Biophys. 31, 16-24. 
Monkos K., Turczynski B. (1991). Determination of the axial ratio of globular proteins in aqueous solution using viscometric measurements. Int. J. Biol. Macromol. 13, 341344.

Pamies R., Hernández J.G., del Carmel López Martínez M., Garcia de la Torre J. (2008). Determination of intrinsic viscosities of macromolecules and nanoparticles. Comparison of single-point and dilution procedures. Colloid. Polym. Sci. 286, 1223-1231.

Pérez J., Zanotti J-M., Durand D. (1999). Evolution of the internal dynamics of two globular proteins from dry powder to solution. Biophys. J. 77, 454-469.

Roth C.M., Neal B.L., Lenhoff A.M. (1996). Van der Waals interactions involving proteins. Biophys. J. 70, 977-987.

Smith L.J., Sutcliffe M.J., Redfield C., Dobson C.M. (1993). Structure of hen lysozyme in solution. J. Mol. Biol. 229, 930-944.

Squire P.G., Himmel M.E. (1979). Hydrodynamics and protein hydration. Arch. Biochem. Biophys. 196, 165-177.

Taborek P., Kleiman R.N., Bishop D.J. (1986). Power-law behavior in the viscosity of supercooled liquids. Phys. Rev. B 34, 1835-1840.

Takashima S. (2001). The structure and dipole moment of globular proteins in solution and crystalline states: use of NMR and X-ray databases for the numerical calculation of dipole moment. Biopolymers 58, 398-409.

Turula V.E., de Haseth J.A. (1996). Particle beam LC/FT-IR spectrometry studies of biopolymer. Conformations in reversed - phase HPLC separations: native globular proteins. Anal. Chem. 68, 629-638.

Vinogradov GV, Malkin AYa. (1980). Rheology of Polymers. Mir, Moscow, 1980.

Woods K.N. (2010). Solvent-induced backbone fluctuations and the collective librational dynamics of lysozyme studied by terahertz spectroscopy. Phys. Rev. E 81, 031915.

Yagi N., Ohta N., Matsuo T. (2009). Structure of amyloid fibrils of hen egg white lysozyme studied by microbeam Xray diffraction. Int. J. Biol. Macromol. 45, 86-90.

Young E.G. (1963). Occurrence, classification, preparation and analysis of proteins. [In:] Florkin M., Stolz E.H. (eds.) Comprehensive biochemistry. Amsterdam, pp.22.

Zhou H.X. (1995). Calculation of translational friction and intrinsic viscosity. Application to globular proteins. Biophys. J. 69, 2298-2303.

Zimmerman S.B., Minton A.P. (1993). Macromolecular crowding: biochemical, biophysical, and physiological consequences. Annu. Rev. Biophys. Biomol. Struct. 22, 27-65. 